\title{
Recent Trends in Breast Cancer Incidence and Mortality in Germany
}

\author{
Alexander Katalinic Ron Pritzkuleit Annika Waldmann \\ Institut für Krebsepidemiologie e.V., Universität zu Lübeck, Germany
}

\section{Key Words}

Breast cancer · Incidence · Mortality - Cancer registration - Hormone replacement therapy

\section{Summary}

Background: Breast cancer is the most common cancer among women in Germany with high public health impact. In the last decade rapid changes in risk factor patterns, early breast cancer detection, and therapy have taken place. Their effects on breast cancer epidemiology in Germany are described. Materials and Methods: A register-based survey using recent incidence data from German cancer registries was performed. Mortality data were provided by the Central Federal Statistical Office. We calculated age-standardized rates and 5- and 10-year trends. Results: Breast cancer incidence increased until the year 2002, thereafter a discreet decline occurred until $2005(-6.8 \%)$. In the age group 50-59 years this reduction was most pronounced (-12\%). Mortality declined from $1996 / 7$ to $2004 / 5$ by $19 \%$, with the strongest effect in women younger than 55 years (approximately $30 \%$ ). Regional patterns of breast cancer incidence and mortality revealed differences within Germany of greater than $30 \%$. Conclusion: Declining hormone replacement therapy prescription is the most likely factor to explain the drop in breast cancer incidence. The reduction in mortality might be caused by better therapy and enhanced early detection during the last decade. Differences in breast cancer incidence and mortality between Eastern and Western Germany give reason for further research and discussion. $\overline{\text { Schlüsselwörter }}$

Brustkrebs · Inzidenz · Mortalität · Krebsregistrierung · Hormonersatztherapie

\section{Zusammenfassung}

Hintergrund: Brustkrebs ist die häufigste Tumorart bei Frauen in Deutschland und besitzt einen großen PublicHealth-Impact. In den letzten 10 Jahren haben sich Risikofaktoren, Früherkennung und Therapie des Mammakarzinoms deutlich verändert. Die Effekte auf die Epidemiologie des weiblichen Brustkrebses werden beschrieben. Material und Methoden: Mittels aktueller deutscher Krebsregisterzahlen zur Brustkrebsinzidenz wurde eine registerbasierte Analyse vorgenommen. Außerdem wurden Mortalitätsdaten des Deutschen Statistischen Bundesamtes genutzt. Berechnet wurden altersstandardisierte Raten (Europastandard) sowie 5- und 10-JahresTrends. Ergebnisse: Bis zum Jahr 2002 stieg die Brustkrebsinzidenz an, danach ist ein dezenter Abfall bis 2005 zu beobachten (-6.8\%). Am stärksten war der Abfall in der Altersgruppe 50-59 Jahre ausgeprägt (-12\%). Die Mortalität ging von $1996 / 7$ bis $2004 / 5$ um $19 \%$ zurück. Der stärkste Rückgang zeigt sich für Frauen bis 55 Jahre (ca. $30 \%)$. Regionale Muster der Inzidenz und Mortalität deuten auf Unterschiede von mehr als 30\% innerhalb von Deutschland hin. Schlussfolgerungen: Ein Rückgang der Hormonersatztherapie-Verordnung ist der wahrscheinlichste Faktor, der den Abfall der Brustkrebsinzidenz erklärt. Die Reduktion der Mortalität wird wahrscheinlich durch die optimierten Therapieverfahren und die verbesserte Früherkennung in den letzten 10 Jahren hervorgerufen. Die großen Unterschiede in Inzidenz und Mortalität zwischen Ost- und Westdeutschland geben Anlass für weitere Untersuchungen und Diskussionen.

\begin{tabular}{ll}
\hline KARGER & @ 2009 S. Karger GmbH, Freiburg \\
Fax +497614520714 & Accessible online at: \\
Information@Karger.de & www.karger.com/brc \\
www.karger.com &
\end{tabular}




\section{Introduction}

Breast cancer is the most common cancer in women worldwide. The International Agency for Research in Cancer (IACR) estimates more than 1.15 million new breast cancer cases every year [1]. Highest incidence rates are found in North America, Northern and Western Europe, and Australia (ranging from 83 to 101 cases per 100,000 women, age-standardized by world standard population), lowest rates in Africa and Asia (9-33/100,000). These estimates are based on worldwide cancer registration. In 2000 , less than $20 \%$ of the world's population was covered by cancer registration and $35 \%$ by vital statistics schemes based on medically certified causes of death [2]. Cancer registration in Germany has a long tradition. The first incidence register started in Hamburg in 1926. During the Second World War registration came to a rest, but started again in 1952 in the area of the former German Democratic Republic. In 1967 the cancer registry of Saarland was founded. In 1995 a German federal law of cancer registry forced all federal states to implement epidemiological cancer registration at the state level until the year 1999. In most parts of Germany cancer registration is implemented today, but in some regions it is still under construction with no reliable data available $[3,4]$. But breast cancer shows, compared to other tumour entities, the highest level of coverage, completeness, and data quality in the epidemiological cancer registration in Germany [5].

Not only from the viewpoint of cancer epidemiology, breast cancer is one of the most interesting and important cancers in Germany as shown by the following points: i) Breast cancer has high public health importance and impact for Germany: it is the most common cancer in women $(57,000$ cases every year, $27.8 \%$ of all registered female cancers). Breast cancer occurs in 'younger' women (median age at diagnosis 63 years, 6 years earlier than for all cancer sites) [5]. Although survival after breast cancer is rather good (5-year relative survival rate $81 \%$ ), every year about 18,000 women die of breast cancer. Breast cancer causes costs of almost 2 billion Euros per year ( $0.8 \%$ of the total health costs) [6]. ii) Breast cancer shows rather rapid changes in risk factor prevalence. In 2002, results of the Women Health Initiative (WHI) proved an increased risk $(+27 \%)$ for breast cancer after hormone replacement therapy (HRT) [7]. Following the WHI publication, prescription of HRT decreased world-wide. This might be the biggest change in prescription practice that was ever observed in the world [8-11]. After the fall in HRT prescription the breast cancer incidence fell subsequently indicating a cause-effect relationship between HRT and female breast cancer [12,13]. A new analysis of the WHI study shows that the formerly published results of the WHI underestimated the effect of HRT: a woman who stays on HRT for at least 5 years, doubles her risk for breast cancer every year [14]. Whether a further decrease in HRT prescription and a subsequent decrease of breast cancer incidence will be observed, remains to be investigated. iii) In the last decade the public focus in cancer was set on breast cancer. This clearly increased breast cancer awareness among the public, stakeholders, and politicians. Early detection of breast cancer was improved by different activities such as quality assured mammography (since 2001 in the federal state of Schleswig-Holstein) [15] and mammography screening (since 2001 pilot projects, nation-wide implementation started in 2004) [16, 17]. Therapy was optimized by disease management programs, creation of breast cancer centers with national certification, and new therapeutic procedures (e.g. sentinel lymph node technique, new chemotherapeutics).

These points could and should have an impact on breast cancer epidemiology in Germany. Incidence and mortality trends are likely to be affected one way or the other. In this publication we describe population-based incidence and mortality trends for female breast cancer in Germany from 1996 to 2005 based on most recent data from German epidemiological cancer registries.

\section{Material and Methods}

This analysis was performed as a register-based survey using breast cancer incidence data provided by the German population-based cancer registries. Breast cancer was defined according to the ICD-10 classification as C50 (invasive breast cancer) and restricted to women. Incidence data were collected from 9 different German federal state population-based cancer registries covering 14 federal states (table 1). Data were provided in an aggregated form (cases by 5-year age groups and year). For 2 states (Baden-Wuerttemberg and Hesse) no incidence data were available. Only a few cancer registries were able to provide complete data starting from 1996. According to the previous and latest issues of 'Cancer in Germany' [5], registration of female breast cancer is estimated to be complete ( $=$ registration of more than $90 \%$ of expected breast cancers) since the year 2000 for nearly all included cancer registries. Therefore, we mainly present incidence data from 2000 to 2005. Incidence data of the participating registries from 1997 to 2005 were pooled to the 'German incidence pool', but Bavaria and Berlin were excluded because of incomplete data, especially in the period from 1997 to 2002, which would lead to biased trend analyses [12]. Rate of DCO cases (death certificate only) in the incidence pool from 1997 to 2005 was $10.0 \%$ for all age groups and $4.7 \%$ for the age group 50-69 years, respectively. Mortality data for the time period were provided by the central Federal Statistical Office [18]. Incidence and mortality are given as rate per 100,000 women (age-standardized rates according to the European standard (EASR)). Trends in incidence and mortality were assessed as relative differences between the combined years 2004/2005 and 2000/2001 (5-year trend) and 1996/1997 (10-year trend), respectively.

\section{Results}

Incidence data were not available for all regions of Germany (table 1), but from 2000 to 2005 a population of 22.9 million women (= $54 \%$ of 42 million women) was under active and complete cancer registration. In this time period about 170,000 incident breast cancers were registered. A crude estimate based on these numbers would lead to approximately 
Table 1. Age-standardized breast cancer incidence and mortality rates; data source incidence: population-based cancer registries, mortality: Federal Statistical Office

\begin{tabular}{|c|c|c|c|c|c|c|}
\hline \multirow[t]{2}{*}{ Federal state } & \multirow{2}{*}{$\begin{array}{l}\text { Population in } \\
2005 \text {, million }\end{array}$} & \multicolumn{2}{|c|}{ Incidence EASR /100,000 } & \multicolumn{3}{|c|}{ Mortality EASR /100,000 } \\
\hline & & $2000 / 1$ & $2004 / 5$ & $1996 / 7$ & $2000 / 1$ & $2004 / 5$ \\
\hline Baden-Wuerttemberg & 5.6 & - & - & 30.9 & 27.7 & 25.8 \\
\hline Bavaria & 6.4 & 105.3 & 112.5 & 31.2 & 28.4 & 27.5 \\
\hline Berlin & 1.7 & 85.4 & 89.6 & 30.0 & 26.4 & 25.1 \\
\hline Brandenburg & 1.3 & 84.3 & 88.5 & 23.5 & 24.9 & 23.0 \\
\hline Bremen & 0.4 & 114.3 & 106.9 & 35.3 & 31.0 & 25.1 \\
\hline Hamburg & 0.9 & 106.8 & 103.2 & 35.7 & 30.1 & 29.4 \\
\hline Hesse & 3.1 & - & - & 33.4 & 29.0 & 26.6 \\
\hline Mecklenburg-West Pomerania & 0.9 & 88.8 & 88.9 & 25.2 & 22.9 & 21.4 \\
\hline Lower Saxony ${ }^{\mathrm{a}}$ & 4.1 & 105.5 & 111.8 & 32.6 & 29.4 & 27.7 \\
\hline North Rhine-Westphalia ${ }^{\mathrm{b}}$ & 9.3 & 107.0 & 95.0 & 32.3 & 29.9 & 28.7 \\
\hline Rhineland-Palatinate & 2.1 & 95.9 & 96.1 & 33.3 & 29.1 & 29.1 \\
\hline Saarland & 0.5 & 110.6 & 104.2 & 35.2 & 32.9 & 29.9 \\
\hline Saxony & 2.2 & 85.5 & 85.3 & 25.0 & 22.3 & 20.6 \\
\hline Saxony-Anhalt & 1.3 & 75.4 & 81.1 & 25.4 & 24.3 & 22.7 \\
\hline Schleswig-Holstein & 1.4 & 142.1 & 131.2 & 34.9 & 30.8 & 28.0 \\
\hline Thuringia & 1.2 & 85.5 & 87.6 & 25.5 & 23.1 & 20.2 \\
\hline Total $^{\mathrm{c}}$ & $42\left(14.7^{\mathrm{c}}\right)$ & 97.6 & 96.6 & 31.0 & 27.9 & 26.5 \\
\hline
\end{tabular}

${ }^{\mathrm{a}}$ Incidence: only district Weser-Ems, 1.25 million female population.

bIncidence: only district Muenster, 1.34 million female population.

${ }^{\mathrm{c}}$ German incidence pool, covering approx. $35 \%$ of female German population, excluding Baden-Wuerttemberg and Hesse (no data) and Bavaria and Berlin (due to low completeness in early years [12]).

EASR $=$ Age-standardized rate according to European standard population.

Fig. 1. Trends in a age-standardized breast cancer incidence and $\mathbf{b}$ mortality in Germany. EASR $=$ Age-standardized rate according to European standard population. a) Incidence

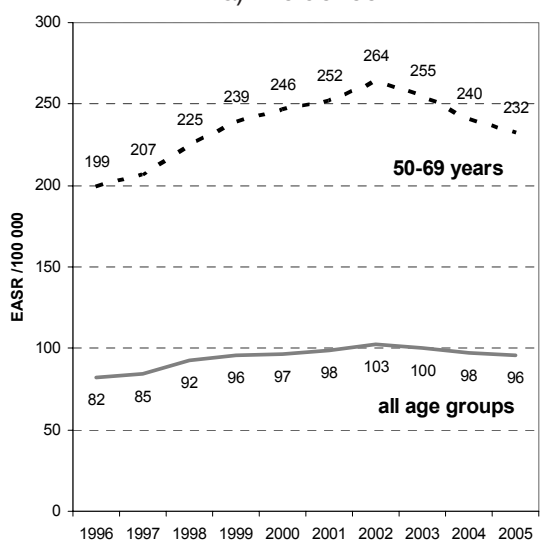

b) Mortality

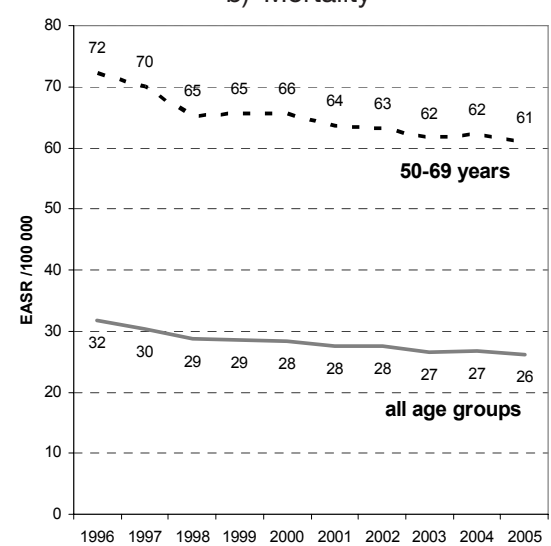

525,000 incident breast cancer cases for Germany in a 10-year period (1996-2005). Data of the German incidence pool indicate that breast cancer incidence increased until 2002. Thereafter a slight decrease $(-6.8 \%)$ could be observed until the year 2005. These trends were more pronounced in the age group from 50 to 69 years (-12\% from 2002 to 2005) than in any other age group (fig. 1 a, table 1 ).

Between 1996 and 2005, 106,740 female breast cancer deaths occurred in Germany. Breast cancer mortality showed a steady decrease in the last 10 years for all age groups $(-19 \%)$ as well for the age group $50-69$ years $(-15 \%)$ (fig. 1 b, table 1).

Regional patterns of breast cancer incidence and mortality are displayed in figure 2 . The lowest breast cancer incidence is found in the eastern parts of Germany (Berlin, Brandenburg, Mecklenburg-West Pomerania, Saxony, Saxony-Anhalt, Thuringia) and the highest incidence rate is found in Northern Germany (Schleswig-Holstein, Bremen, Hamburg, Lower Saxony). Similar patterns are seen for breast cancer mortality (fig. 2).

Five-year trends in incidence depend on age and region. Increasing incidence rates were seen in the younger and older age groups, while the age group from 50 to 59 years shows a decrease of $10 \%$ (fig. 3). Negative 5-year trends in breast cancer mortality were observed for all age groups, but the trend was most pronounced in the younger age groups. Trends in incidence and mortality rates on the state level are shown in figure 4 . The 5- and the 10-year differences in mortality were highest in Bremen, lowest in Brandenburg. 


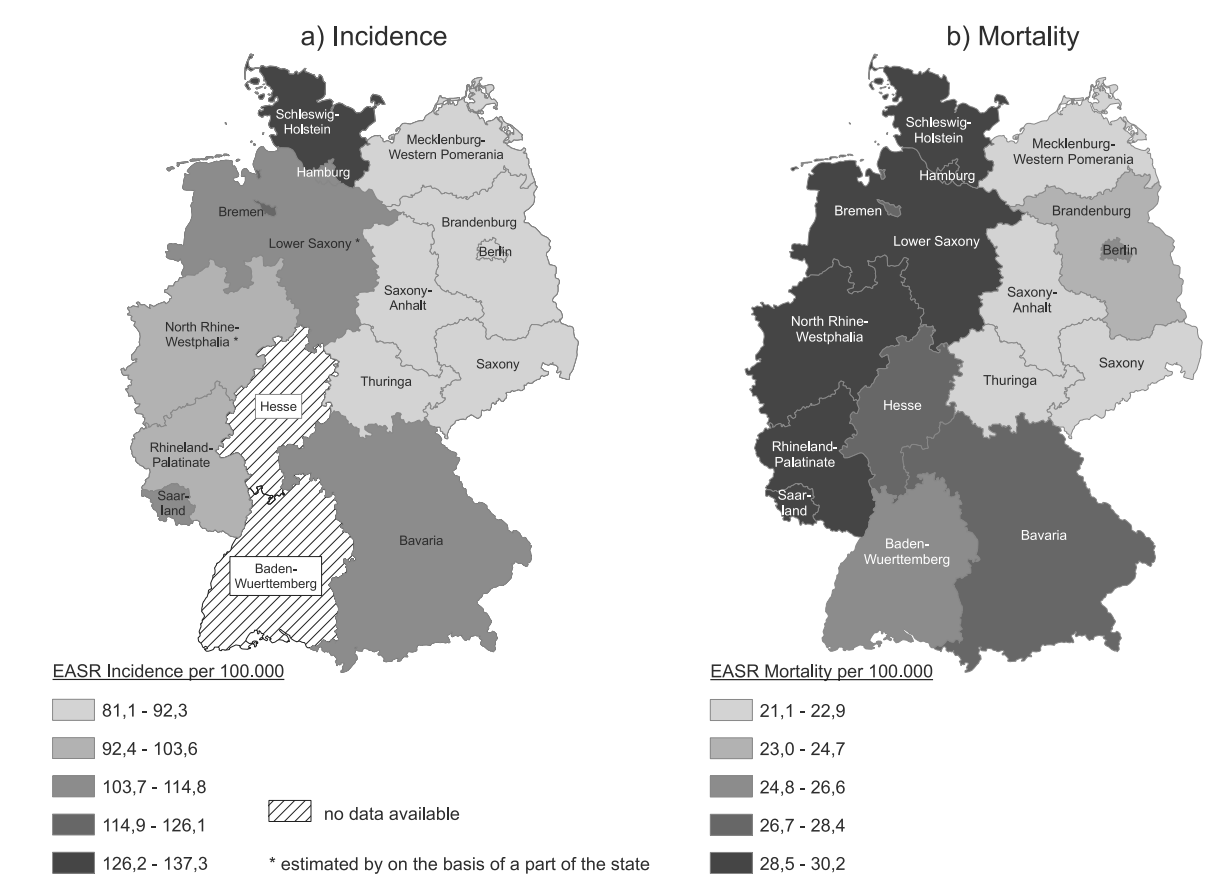

Fig. 2. Geographical patterns (by federal state) in $\mathbf{a}$ breast cancer incidence and $\mathbf{b}$ mortality in Germany, 2000-2005. EASR = Age-standardized rate according to European standard population.

\section{Discussion}

As shown above, breast cancer incidence increased until the year 2002 (fig. 1 a). Different mechanisms may have contributed to this increase: i) increase in well-known and proven risk factors such as higher age at first birth, nulliparity, prescription of birth control pills; ii) increased prescription of HRT; iii) utilization of early detection programs; iv) enhanced completeness of cancer registration. It is unclear which of these factors contributed predominantly to the increase in incidence, probably all factors played a role. Interestingly, a decrease in incidence can be observed since 2002 - the year in which the results of the WHI study were published [7]. Agespecific analyses show that the observed discrete decrease could be attributed to a steep incidence fall in the age group $50-59$ years (about $-12 \%$ ). This is the age group that is most likely to receive HRT. Today the association between the decline in HRT prescription and the fall of breast cancer incidence could be deemed to be causal. This association was first described by Clarke et al. [13] and Ravdin et al. [19]. Meanwhile an analysis of German data confirmed declining trends in HRT usage followed by a fall of breast cancer incidence [12]. All authors discussed other possibilities than HRT for the incidence decline, but only HRT was left over as most probable causal factor [20].

The regional patterns of breast cancer incidence and mortality (fig. 2) reveal a remarkable result. Variation in breast cancer incidence and mortality between the federal states is high. Incidence is about 35\% lower in East Germany than in West Germany. A similar pattern applies to mortality. These patterns might be caused by a different distribution of breast cancer risk factors within Germany. Women that live in the region of the former German Democratic Republic (East Germany) might have another reproductive history than women that live in the other areas of Germany. Within the period of 1975-1990, pregnancy numbers were higher in East Germany (approximately 1.7 births per woman) than in West Germany (approximately 1.3) [21]. Moreover, women in the eastern part of Germany were (and are still) younger at the time of their first pregnancy. The difference is approximately 3 years for women of the birth cohort 1952-1956 and 4 years for the birth cohort 1962-1966 [6]. HRT prescription was markedly lower in East Germany than in West Germany [12]. While almost all western federal states show negative 5-year incidence trends (fig. 4), an increase in age-standardized breast cancer incidence could be observed in the eastern parts of Germany. It seems to be very likely that the mentioned differences in risk factor distribution led to the present incidence pattern. Especially regional differences in HRT prescription have to be discussed under public health aspects in the future. Even after the nation-wide decline of HRT prescription, differences in prescription by a factor of 2 persist [12].

Considering the trend in incidence rates until 2002, increasing breast cancer mortality rates might be expected. But the opposite is the case (fig. 1 b). Since 1996, age-standardized mortality rate decreased from 32 to 26 deaths per 100,000 women $(-23 \%)$. If more women get breast cancer but less women die from breast cancer in the same period of time, survival rates must improve. As shown by Brenner et al. [22], 5year survival rates increased during the last decades in Germany, which might be due to a changed pattern of tumour stage distribution or due to optimized therapy regimens. The latter can be evaluated by means of stage-specific 5-year survival rates during different time periods as recently done by Kray- 
Fig. 3. Differences in age-specific breast cancer incidence (2004/5-2000/1, 5 years) and mortality (2004/5-2000/1, 5 years, and 2004/51996/7, 10 years).
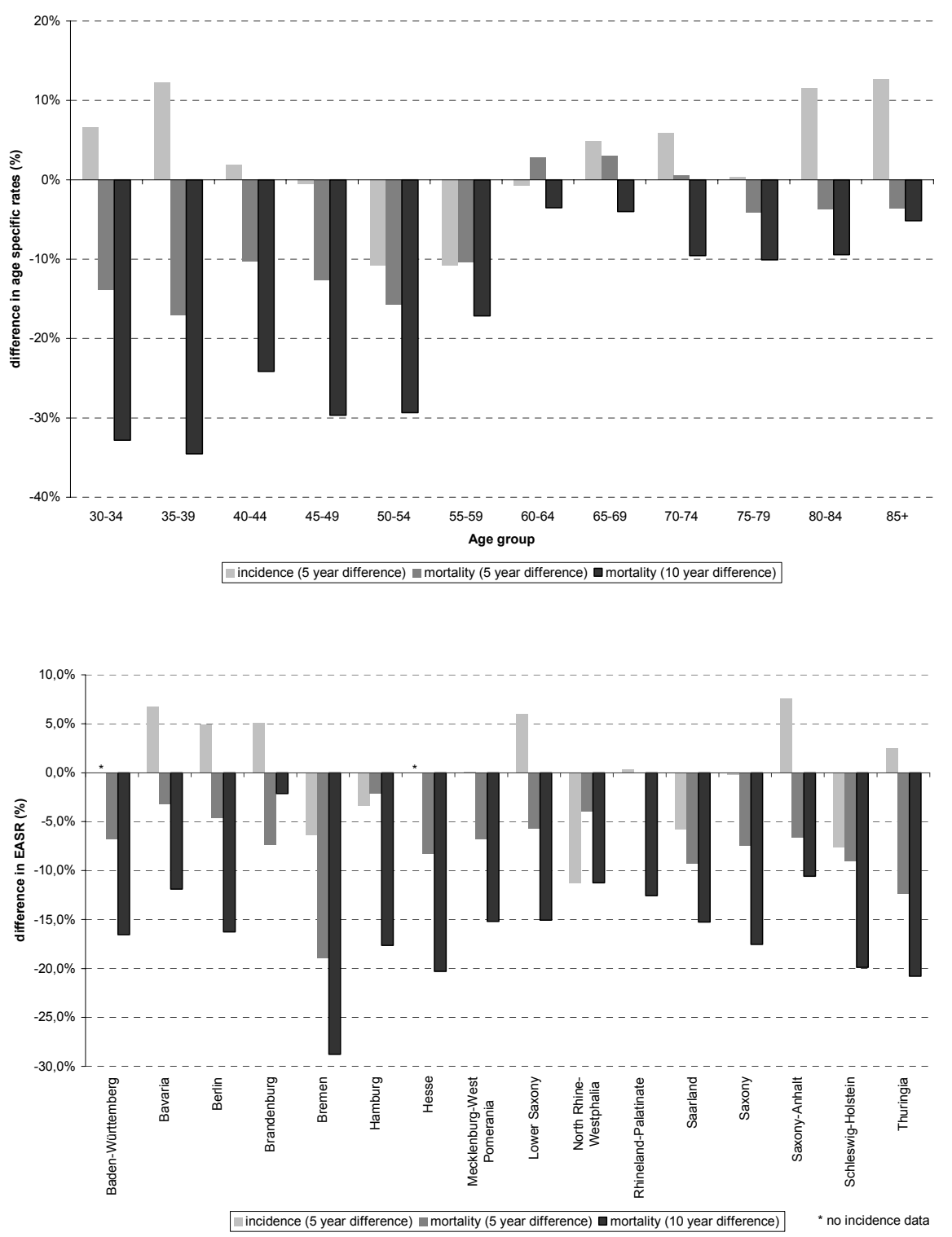

Fig. 4. Differences in age-standardized breast cancer incidence (2004/5-2000/1, 5 years) and mortality (2004/5-2000/1, 5 years, and 2004/51996/7, 10 years). tigated more precisely in the future. Early detection in younger women should not have the potential to cause such a large decrease. Screening studies state a non-significant mortality reduction in the region of up to $20 \%$ [24, 25]. Maybe younger women with breast cancer have a greater benefit from new therapies than older women.

In conclusion, female breast cancer mortality has been decreasing during the last decade. The highest decrease was seen in the age group up to 50-59 years. Breast cancer incidence increased until 2002 and has shown a slight decrease since then. Incidence changes were most pronounced in the age group 50-59 years. Even 20 years after the reunion of the two German states east-west differences for incidence and mortality are seen which might emerge from differing prevalence of breast cancer risk factors within the years 1950-1990 in the former two states. Further development of breast cancer incidence and mortality hardly can be predicted. Due to the nation-wide implementation of mammography screening, an 
incidence increase is probable, even if the ongoing decline in HRT prescription should lead to less breast cancer cases. But will the mortality decline go on? Will there be a $25 \%$ mortality reduction as expected after the introduction of nation-wide mammography screening? Good cancer registration in Germany will give an opportunity to answer these questions in the future.

\section{Acknowledgment}

Special thanks go to all German cancer registries providing actual incidence data: M. Meyer (Population-Based Cancer Registry of Bavaria),
A. Eberle (Bremen Cancer Registry), S. Hentschel (Hamburg Cancer Registry), K. Kraywinkel (Cancer Registry of North Rhine-Westphalia), J. Kieschke (Population-Based Cancer Registry of Lower Saxony), K. Emrich (Cancer Registry of Rhineland-Palatinate), C. Stegmaier (Population-Based Cancer Registry of Saarland), M. Holzmann (Cancer Registry of Schleswig-Holstein), R. Stabenow (Common Cancer Registry of the Federal States of Berlin, Brandenburg, Mecklenburg-West Pomerania, Saxony-Anhalt, Saxony, and Thuringia).

\section{Conflict of Interest}

None of the authors have any conflict of interest to declare.

\section{References}

1 Ferlay J, Bray F, Pisani P, Parkin DM: Globocan 2002: Cancer Incidence, Mortality and Prevalence Worldwide. IARC cancerbase no. 5, version 2.0. Lyon, IARCPress, 2004.

2 Boyl P, Levin B: World Cancer Report 2008. Lyon, WHO/AIRC, 2009.

3 Freie und Hansestadt Hamburg. Behörde für Gesundheit: Hamburger Krebsdokumentation 1999 bis 2001. Neuerkrankungen und Todesursachenstatisitik. Hamburg, Alsterdruck, 2004.

4 Katalinic A: Epidemiologische Krebsregistrierung in Deutschland. Bestandsaufnahme und Perspektiven. Bundesgesundheitsblatt 2004;47:422-428.

5 Robert Koch-institute and the Association of Population-Based Cancer Registries in Germany: Cancer in Germany 2003-2004. Incidence and Trends, 6th ed. Saarbrücken, 2006.

6 Statistisches Bundesamt: Geburten in Deutschland (births in Germany). Wiesbaden, Statistisches Bundesamt, 2007.

7 Rossouw JE, Anderson GL, Prentice RL, LaCroix AZ, Kooperberg C, Stefanick ML, Jackson RD, Beresford SA, Howard BV, Johnson KC, Kotchen $\mathrm{JM}$, Ockene J: Risks and benefits of estrogen plus progestin in healthy postmenopausal women: principal results from the women's health initiative randomized controlled trial. JAMA 2002;288:321-333.

$\checkmark 8$ Faber A, Bouvy ML, Loskamp L, van de Berg PB, Egberts TC, de Jong-van den Berg LT: Dramatic change in prescribing of hormone replacement therapy in The Netherlands after publication of the million women study: a follow-up study. Br J Clin Pharmacol 2005;60:641-647.

9 Main P, Robinson M: Changes in utilisation of hormone replacement therapy in Australia following publication of the findings of the women's health initiative. Pharmacoepidemiol Drug Saf 2008;17: 861-868.
10 Menon U, Burnell M, Sharma A, Gentry-Maharaj A, Fraser L, Ryan A, Parmar M, Hunter M, Jacobs I: Decline in use of hormone therapy among postmenopausal women in the united kingdom. Menopause 2007; 14:462-467.

11 Silverman BG, Kokia ES: Use of hormone replacement therapy, 1998-2007: sustained impact of the women's health initiative findings (February). Ann Pharmacother 2009, Epub ahead of print, PMID 19193581.

12 Katalinic A, Lemmer A, Zawinell A, Rawal R, Waldmann A: Trends in hormone therapy and breast cancer incidence - results from the German network of cancer registries. Pathobiology 2009;76: 90-97.

13 Ravdin PM, Cronin KA, Howlader N, Berg CD, Chlebowski RT, Feuer EJ, Edwards BK, Berry DA: The decrease in breast-cancer incidence in 2003 in the United States. N Engl J Med 2007;356:16701674.

14 Chlebowski RT, Kuller LH, Prentice RL, Stefanick ML, Manson JE, Gass M, Aragaki AK, Ockene JK, Lane DS, Sarto GE, Rajkovic A, Schenken R, Hendrix SL, Ravdin PM, Rohan TE, Yasmeen S, Anderson G: Breast cancer after use of estrogen plus progestin in postmenopausal women. N Engl J Med 2009;360:573-587.

15 Katalinic A, Bartel C, Raspe H-H, Schreer I: Beyond mammography screening: quality assurance in breast cancer diagnosis (the QuaMaDi project). $\mathrm{Br}$ J Cancer 2007;96:157-161.

16 Diekmann S, Diekmann F: (Mammography screening in Germany). Radiologe 2008;48:17-25.

17 Urbschat I, Kieschke J, Schlanstedt-Jahn U, von Gehlen S, Thiel A, Jensch P: (Contributions of the epidemiological cancer registries to the evaluation of mammography screening in Germany). Gesundheitswesen 2005;67:448-454.

18 Healthmonitoring in Germany: keyword: mortality; accessed 02/24/2009, www.Gbe-bund.De/gbe1/ pkg_isgbe5.Prc_isgbe? P_uid = gast and p_aid $=$ and p_sprache $=e$.
19 Clarke CA, Glaser SL, Uratsu CS, Selby JV, Kushi LH, Herrinton LJ: Recent declines in hormone therapy utilization and breast cancer incidence: clinical and population-based evidence. J Clin Oncol 2006;24:e49-e50.

20 Stang A: Decline in hormone replacement prescription and fall in breast cancer incidence - an epidemiological discourse. Dtsch Arztebl Int 2008; 105:303-309.

21 Beske F, Becker E, Krauss C, Katalinic A, Pritzkuleit R: Gesundheitsversorgung 2050 - Prognose Deutschland und Schleswig-Holstein. Kiel, Schmidt and Klaunig, 2007.

22 Brenner H, Stegmair C, Ziegler H: Verbesserte Langzeitüberlebensraten von Krebspatienten - die unterschätzen Fortschritte in der Onkologie (long-term survival of cancer patients - underrated progress in oncology). Dtsch Arztebl 2005;102: A2628-A2633.

23 Kraywinkel K: Stadienspezifische relative Überlebensraten beim Mammakarzinom - Ergebnisse aus den Krebsregistern des Saarlands und des Regierungsbezirks Münster. Oder: Warum leben Brustkrebspatientinnen heute länger?: 17 Informationstagung Tumordokumentation der klinischen und epidemiologischen Krebsregister 20.-22. Juni 2007 in Saarbrücken, 2007.

24 Hendrick RE, Smith RA, Rutledge JH 3rd, Smart $\mathrm{CR}$ : Benefit of screening mammography in women aged 40-49: a new meta-analysis of randomized controlled trials. J Natl Cancer Inst Monogr 1997: 87-92.

25 Larsson LG, Andersson I, Bjurstam N, Fagerberg G, Frisell J,Tabar L, Nystrom L: Updated overview of the Swedish randomized trials on breast cancer screening with mammography: age group 40-49 at randomization. J Natl Cancer Inst Monogr 1997:57-61. 